\title{
Evaluation of Compost with different NPK level on pea plant under drought stress
}

\section{Usman Ahmad, Rahmat Wali, Noshin Ilyas, Naizma Batool and Rubina Gul}

Department of Botany, PMAS Arid Agriculture University, Rawalpindi, Pakistan

*Corresponding author email: noshinilyas@ uaar.edu.pk; noshinilyas@yahoo.com

\section{Citation}

Usman Ahmad, Rahmat Wali, Noshin Ilyas, Naizma Batool and Rubina Gul. Evaluation of Compost with different NPK level on pea plant under drought stress. Pure and Applied Biology. Vol. 4, Issue 2, 2015, pp 261-267

Received: $24 / 02 / 2015$

Revised: 13/04/2015

Accepted: $27 / 04 / 2015$

\section{Abstract}

Drought stress is one of the big issues, responsible for reducing crop production in the world. One of the strategies to increase crop yield is use of organic and inorganic fertilizers. The compost and NPK has positive role under drought stress on plant growth. For this purpose, the seeds of two varieties, Barani variety and Hybrid F1 variety of pea plant were purchased from local market, Rawalpindi. The compost and NPK were also purchased from local market, Rawalpindi. In order to study the effect of compost and NPK on pea plant were carried out in Green House of PMAS Arid Agriculture University, Rawalpindi. The combined effect of compost and NPK had showed significant increase in root length of Barani variety $70 \%$ and Hybrid variety $50 \%$, shoot length of Barani variety $59 \%$ and Hybrid variety $70 \%$, soil moisture of Barani variety $33 \%$ and Hybrid variety $37 \%$, relative water content of Barani variety $48 \%$ and Hybrid variety $45 \%$, chlorophyll a of Barani variety $70 \%$ and Hybrid variety $33 \%$, chlorophyll b of Barani variety $43 \%$ and Hybrid variety $18 \%$ and total chlorophyll content of Barani variety is $51 \%$ and Hybrid variety $22 \%$ under the drought stress as compared to the drought control.

Keyword: Pea; Compost; Drought; Fertilizer

\section{Introduction}

Pea (Pisum sativum) is a cool season food legume, has a wide variety of uses. It is the second most important legume in the world for its use [1] and is grown in different regions of the world. It is commonly used in the form of dry pulses, fresh peas and edible podded type [2]. It has been economically grown for the canning industry and traditionally for dry grain [3]. Peas are grown particularly on all types of soil from light sandy to heavy clay. Frequent irrigation tends to increase vegetative growth at the expense of pod formation [4]. The high yield of plant in adequate irrigated conditions is not necessarily correlated to high yield under drought stress [5]. Depending on which stage of growth a plant experiences drought stress, it reacts in a different way to the stress [6]. A local undesirable effect of water stress on crop 
plants is reduction of fresh and dry biomass production [7]. Plant productivity under drought stress is strongly linked to the processes of dry matter partition and temporal biomass division [8]. Plant may be affected by drought at any time of life, but certain stage such as germination and seedling growth are critical [9]. Organic agriculture is one of the ways that can produce high quality crops [10]. Compost and NPK play a vital role to increase the growth in pea plant [11]. The experiment had been conducted to determine the effect of Compost and NPK on pea plant under drought stress.

\section{Materials and Methods}

The present study was carried out to check the effect of Compost and NPK on growth and yield of pea under well-water condition and drought stress (Table-1). Two pea varieties i.e. Barani variety and Hybrid F1 variety were collected from Local Market, Rawalpindi. The compost and NPK were also brought from Local Market, Rawalpindi. Pot experiment was conducted in Green House at Research Area, Department of Botany, Pir Mehr Ali Shah Arid Agriculture University Rawalpindi. Compost was added in soil 1:3 ratio and $0.22 \mathrm{~g}$ of NPK was added in soil per pot. Seeds of both varieties were surface sterilized in $0.1 \%$ mercuric chloride solution for 5 minutes and several times with distilled water. In each earthen pot eight sterilized seeds of Barani variety were sown and were thinned to three after germination. After 40 days of seedlings, the plants of both varieties were imposed to drought stress for 7 days by withholding water.

\section{Soil analysis:}

Gravimetric method [12] was used to for moisture content estimation. Fresh weight of soil was obtained and soil dried in oven at $105^{\circ} \mathrm{C}$ for three days or until constant weight. Dry weight was later on measured and moisture content of soil was calculated in percentage by following formula:

Soil Moisture $\%=$ Wet soil $(\mathrm{g})-$ Dry soil (g) / Dry soil (g) x 100

Plant analysis:

Plant analysis for each treatment were collected and analyzed for different morphological and physiological parameters.

\section{Morphological Parameter:}

For each treatment, two plants were uprooted and separated into root and shoot. After washing root and shoot, Root length (cm) and shoot length $(\mathrm{cm})$ were measured for each treatment at the end of experiment. For each treatment, plants were uprooted, washed afterward and determined the fresh weights of root and shoot. Dry weight of root and shoot was recorded by placing same samples of root and shoot in oven at $65^{\circ} \mathrm{C}$ for each treatment. Fresh and Dry weight of root and shoot were taken in grams $(\mathrm{g})$.

\section{Physiological parameter:}

For each treatment fresh weight of flag leaf was recorded. Same leaves were soaked in water for 24 hours and their turgid weights were obtained. Afterward measuring the weight leaf samples were placed at $70^{\circ} \mathrm{C}$ in oven for 72 hours and dry weight was recorded. Following formula was used:

$\mathrm{RWC}=($ Fresh weight - Dry weight $)$ (Saturated weight - Dry weight) 100

Method of [13] was used for evaluation of total chlorophyll contents $0.2 \mathrm{~g}$ leaf was homogenized in known volume of acetone $(10 \mathrm{ml})$. Filtrate was taken in another set of tubes. Absorbance of extract was recorded at 645, 652 and $663 \mathrm{~nm}$. By using following equations chlorophyll contents were estimated:

Total Chlorophyll content $=\left(\mathrm{A}_{652} \mathrm{X}\right.$ 1000/34.5) 
Chlorophyll a content $=12.7\left(\mathrm{~A}_{663}\right)-2.7$

(A645)

Chlorophyll $\mathrm{b}$ content $=22.9\left(\mathrm{~A}_{645}\right)-4.7$

(A663)

\section{Results and Discussion}

Compost and NPK had significant role on growth parameters of both varieties of pea plant (Pisum sativum). Compost had increased root of barani variety about $58 \%$ and Hybrid variety about $50 \%$ as compared to drought control. NPK had increased root of barani variety is $77 \%$ and Hybrid variety is $46 \%$. The combined effect of compost and NPK had increased root length of Barani variety is $70 \%$ and Hybrid variety is $50 \%$ as compared to control under drought as shown in fig.1.

A significant effect of compost and NPK has been observed on shoot length. As the shoot length of barani variety had increased due to compost is $50 \%$ and Hybrid variety is $77 \%$ as compared to the control under drought. NPK had increased shoot of barani variety is $80 \%$ and Hybrid variety is $77 \%$. The combined effect of compost and NPK had increased root length of Barani variety is $59 \%$ and Hybrid variety is $70 \%$ as compared to control under drought as shown in fig. 2 . Chuan et al., [14] had checked the effect of vermi-compost and NPK on pea plant, comprised seven treatment consisting of three treatments with compost and three treatments with vermin-compost + NPK and one treatment is FYM + NPK. The treatment (vermin-compost + NPK) had showed a positive result on pea plant to increased plant height and pod weight. The pea plant with the application of compost and NPK also comprised best growth under drought stress and had increased root length and shoot length. The compost and NPK has increased the soil moisture of soil under the drought stress. Compost had increased soil moisture of barani variety about $33 \%$ and Hybrid variety about $46 \%$ as compared to drought control. NPK had increased soil moisture of barani variety is $57 \%$ and Hybrid variety is $50 \%$. The combined effect of compost and NPK had increased root length of Barani variety is $33 \%$ and Hybrid variety is $37 \%$ as compared to control under drought as shown in fig.3.

Compost and NPK had played a vital role to increase the relative water content of pea varieties under drought stress. Compost had increased relative water content of Barani variety about $71 \%$ and Hybrid variety about $60 \%$ as compared to drought control. NPK had increased soil moisture of barani variety is $71 \%$ and Hybrid variety is $66 \%$. The combined effect of compost and NPK had increased relative water content of Barani variety is $48 \%$ and Hybrid variety is $45 \%$ as compared to control under drought as shown in fig.4. Sarwar ei al., [15] had reported that compost with and without inorganic fertilizer has significant role to increase the biomass of wheat and rice and also improved soil fertility. The similar effect had been found on pea plant. The compost and NPK had raised the crop production and responsible for improving the soil fertility by increasing soil moisture and relative water content. The chlorophyll a, chlorophyll $\mathrm{b}$ and total chlorophyll content are reduced under drought stress. Compost and NPK are responsible for increasing the chlorophyll a, chlorophyll b and total chlorophyll content of both varieties of pea plant under drought stress Compost had increased Chlorophyll a of Barani variety about $46 \%$ and Hybrid variety about $37 \%$ as compared to drought control. NPK had increased chlorophyll a of barani variety is $70 \%$ and Hybrid variety is $36.76 \%$. The combined effect of compost and NPK had increased chlorophyll a of Barani variety is $70 \%$ and Hybrid variety is 
Table-1. Experiment Layout

\begin{tabular}{|c|c|}
\hline Label & Treatments \\
\hline$T_{\mathrm{O}}$ & Control \pm well-water condition \\
\hline$T_{1}$ & Control \pm drought stress \\
\hline$T_{2}$ & Compost \pm well-water condition \\
\hline$T_{3}$ & Compost \pm drought stress \\
\hline$T_{4}$ & NPK \pm well water condition \\
\hline$T_{5}$ & NPK \pm drought stress \\
\hline$T_{6}$ & Compost and NPK \pm well water condition \\
\hline$T_{7}$ & Compost and NPK \pm drought stress \\
\hline
\end{tabular}

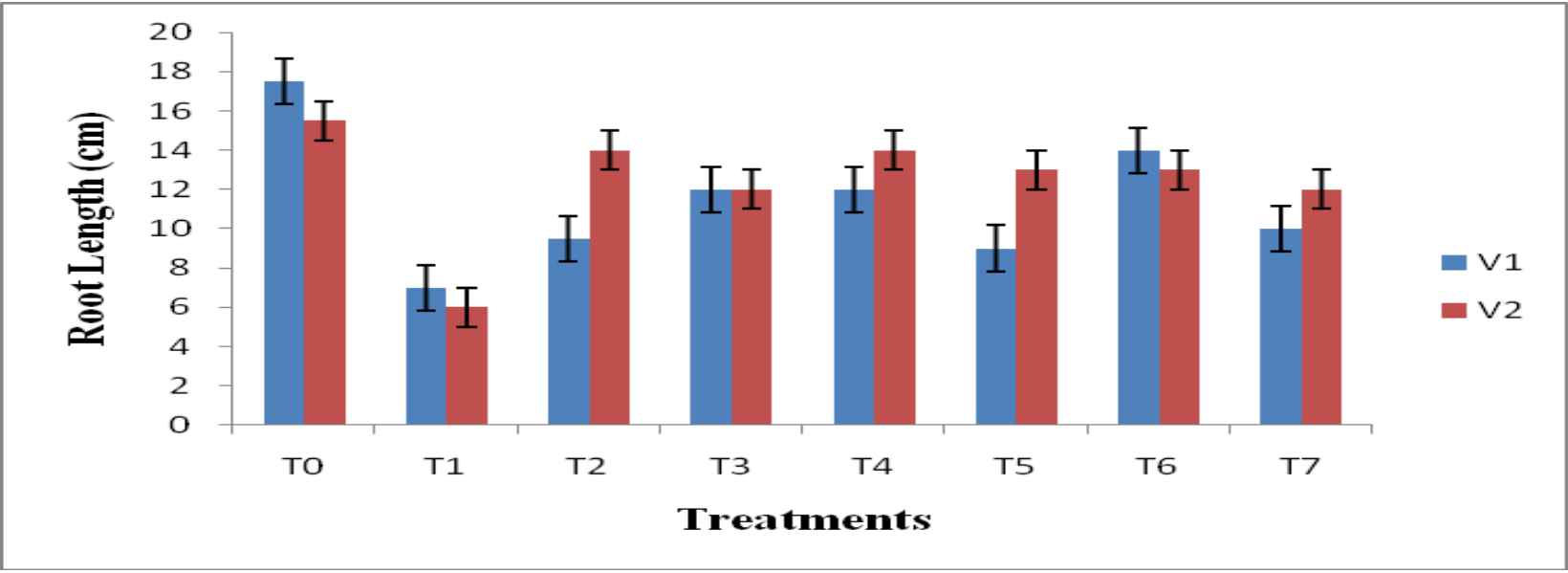

Fig.1. Effect of compost and NPK on root length $(\mathrm{cm})$ of two pea varieties under drought stress

Where $\mathrm{T}_{0}=$ Control \pm well-water condition, $\mathrm{T}_{1}=$ Control \pm drought stress, $\mathrm{T}_{2}=$ Compost \pm well-water condition, $\mathrm{T}_{3}=$ Compost \pm drought stress, $\mathrm{T}_{4}=\mathrm{NPK} \pm$ well-water condition, $\mathrm{T}_{5}=\mathrm{NPK} \pm$ drought stress, $\mathrm{T}_{6}=$ Compost and $\mathrm{NPK} \pm$ well-water condition, $\mathrm{T}_{7}=$ Compost and $\mathrm{NPK} \pm$ drought stress. And $\mathrm{V}_{1}=$ Barani variety, $\mathrm{V}_{2}=$ Hybrid $\mathrm{F} 1$ variety

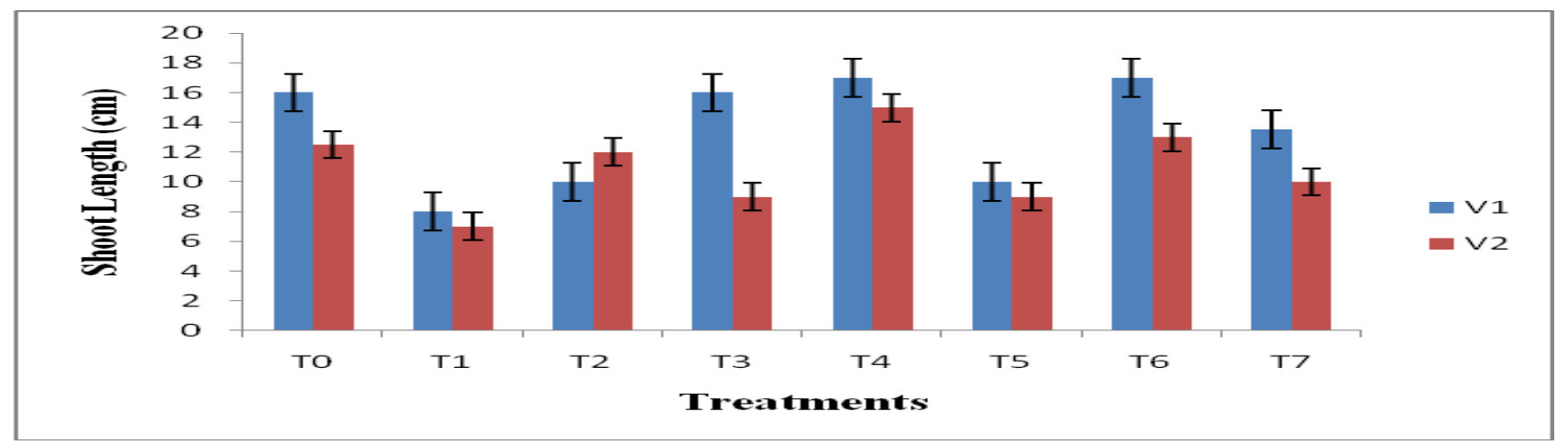

Fig.2. Effect of compost and NPK on shoot length of two pea varieties under drought stress

Where $\mathrm{T}_{0}=$ Control \pm well-water condition, $\mathrm{T}_{1}=$ Control \pm drought stress, $\mathrm{T}_{2}=$ Compost \pm well-water condition, $\mathrm{T}_{3}=$ Compost \pm drought stress, $\mathrm{T}_{4}=\mathrm{NPK} \pm$ well-water condition, $\mathrm{T}_{5}=\mathrm{NPK} \pm$ drought stress, $\mathrm{T}_{6}=$ Compost and NPK \pm well-water condition, $\mathrm{T}_{7}=$ Compost and NPK \pm drought stress. And $\mathrm{V}_{1}=$ Barani variety, $\mathrm{V}_{2}=$ Hybrid $\mathrm{F} 1$ variety 


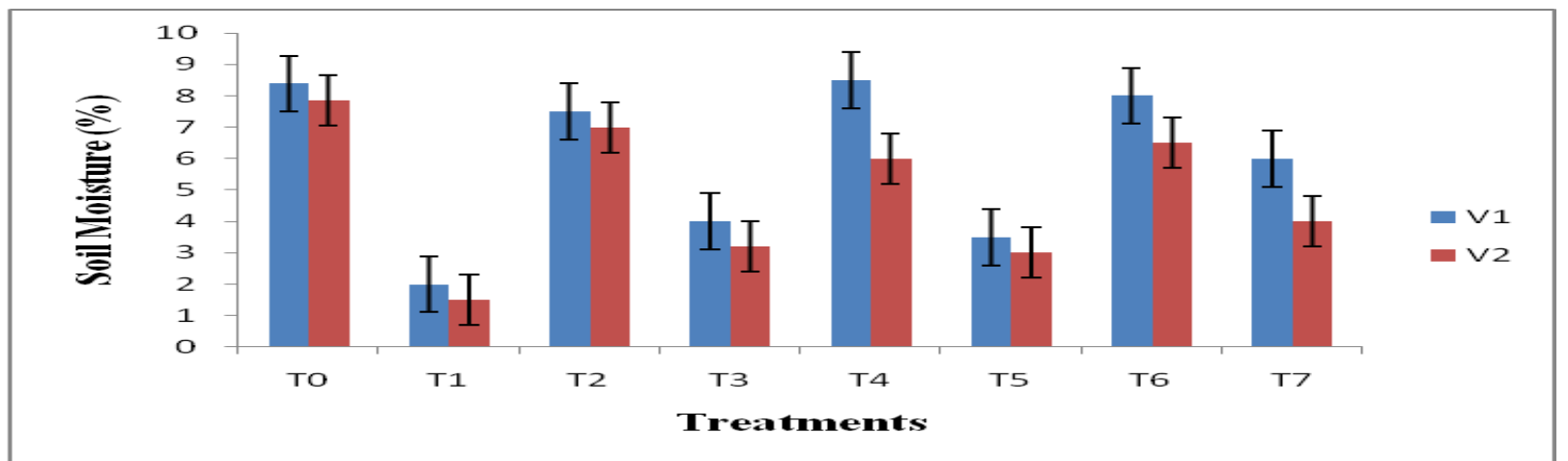

Fig.3. Effect of compost and NPK on soil moisture (\%) of soil under drought stress

Where $\mathrm{T}_{0}=$ Control \pm well-water condition, $\mathrm{T}_{1}=$ Control \pm drought stress, $\mathrm{T}_{2}=$ Compost \pm well-water condition, $\mathrm{T}_{3}=$ Compost \pm drought stress, $\mathrm{T}_{4}=\mathrm{NPK} \pm$ well-water condition, $\mathrm{T}_{5}=\mathrm{NPK} \pm$ drought stress, $\mathrm{T}_{6}=$ Compost and NPK \pm well-water condition, $\mathrm{T}_{7}=$ Compost and NPK \pm drought stress. And $\mathrm{V}_{1}=$ Barani variety, $\mathrm{V}_{2}=$ Hybrid F1 variety

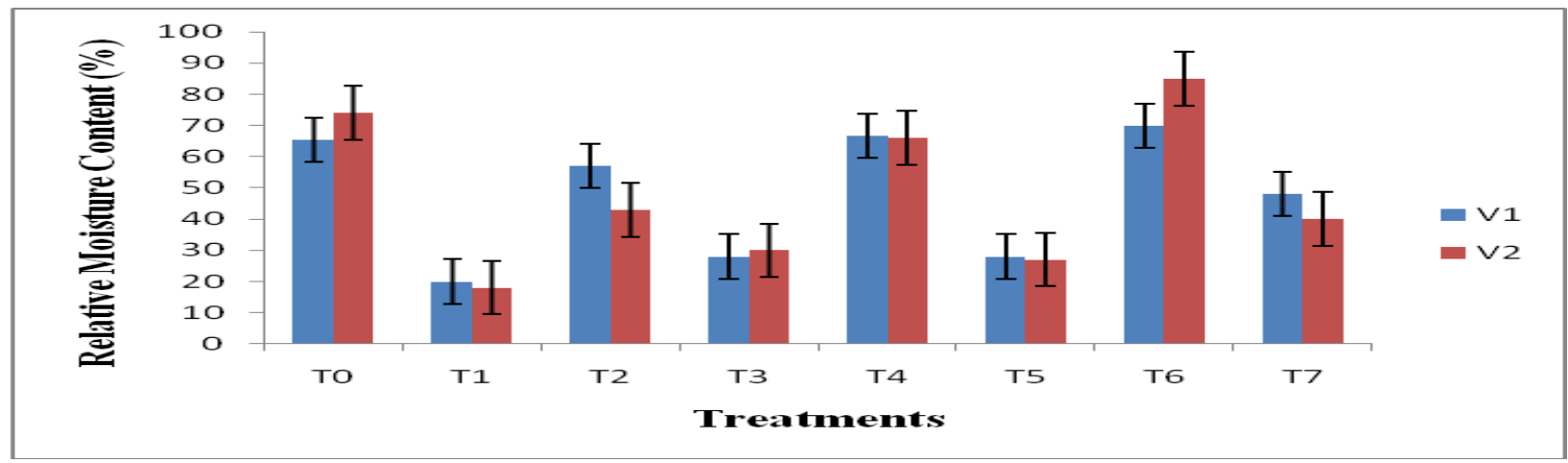

Fig.4. Effect of compost and NPK on relative water (\%) content of two pea varieties under drought stress Where $\mathrm{T}_{0}=$ Control \pm well-water condition, $\mathrm{T}_{1}=$ Control \pm drought stress, $\mathrm{T}_{2}=$ Compost \pm well-water condition, $\mathrm{T}_{3}=$ Compost \pm drought stress, $\mathrm{T}_{4}=\mathrm{NPK} \pm$ well-water condition, $\mathrm{T}_{5}=\mathrm{NPK} \pm$ drought stress, $\mathrm{T}_{6}=$ Compost and NPK \pm well-water condition, $\mathrm{T}_{7}=$ Compost and NPK \pm drought stress. And $\mathrm{V}_{1}=$ Barani variety, $\mathrm{V}_{2}=$ Hybrid F1 variety

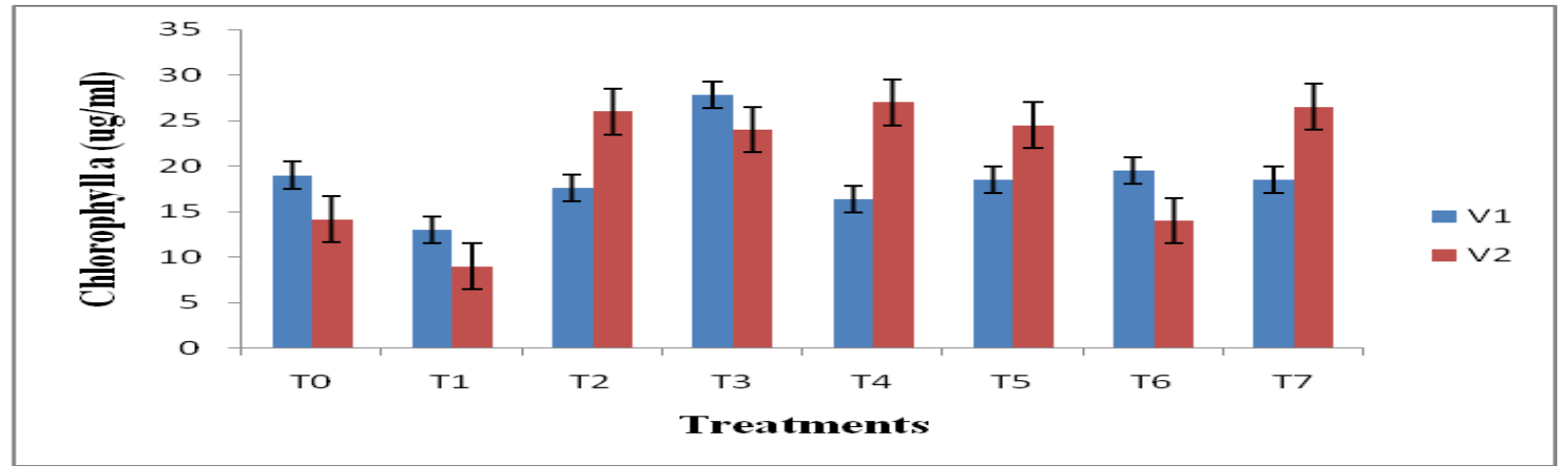

Fig.5. Effect of compost and NPK on chlorophyll a of plant material of two pea varieties under drought stress Where $\mathrm{T}_{0}=$ Control \pm well-water condition, $\mathrm{T}_{1}=$ Control \pm drought stress, $\mathrm{T}_{2}=$ Compost \pm well-water condition, $\mathrm{T}_{3}=$ Compost \pm drought stress, $\mathrm{T}_{4}=\mathrm{NPK} \pm$ well-water condition, $\mathrm{T}_{5}=\mathrm{NPK} \pm$ drought stress, $\mathrm{T}_{6}=$ Compost and NPK \pm well-water condition, $\mathrm{T}_{7}=$ Compost and $\mathrm{NPK} \pm$ drought stress. And $\mathrm{V}_{1}=$ Barani variety, $\mathrm{V}_{2}=$ Hybrid $\mathrm{F} 1$ variety 


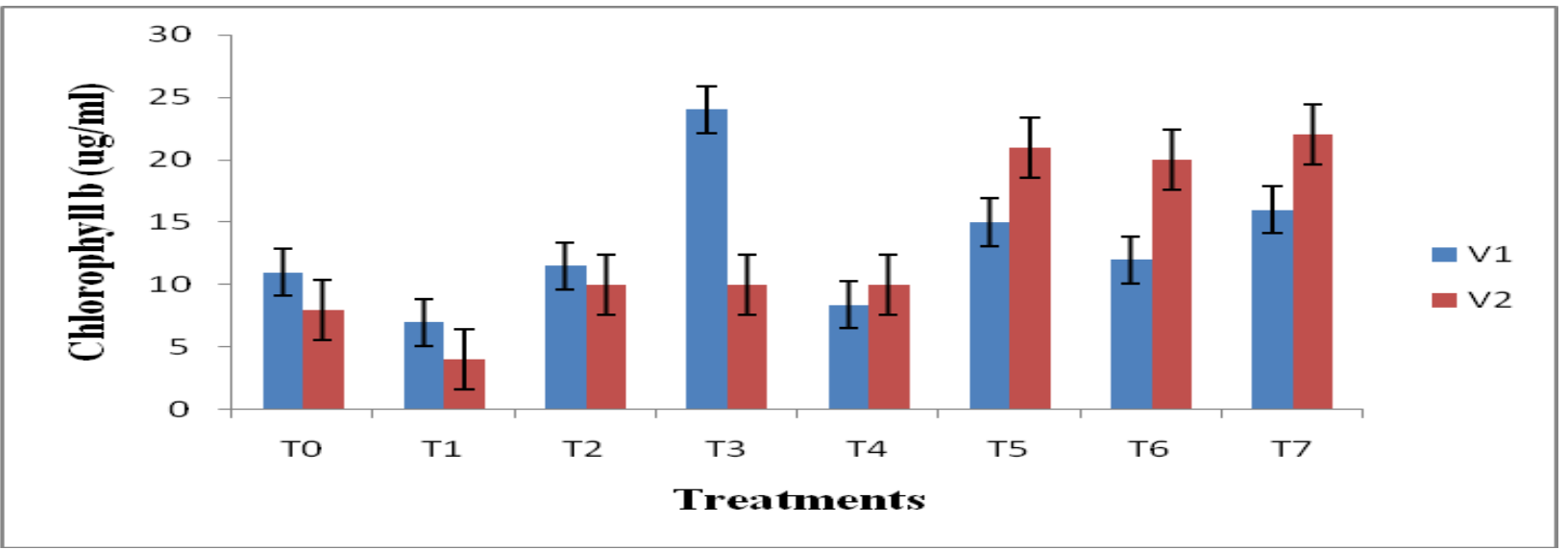

Fig.6. Effect of compost and NPK on chlorophyll $b$ of two pea varieties under drought stress

Where $\mathrm{T}_{0}=$ Control \pm well-water condition, $\mathrm{T}_{1}=$ Control \pm drought stress, $\mathrm{T}_{2}=$ Compost \pm well-water condition, $\mathrm{T}_{3}=$ Compost \pm drought stress, $\mathrm{T}_{4}=\mathrm{NPK} \pm$ well-water condition, $\mathrm{T}_{5}=\mathrm{NPK} \pm$ drought stress, $\mathrm{T}_{6}=$ Compost and NPK \pm well-water condition, $\mathrm{T}_{7}=$ Compost and $\mathrm{NPK} \pm$ drought stress. And $\mathrm{V}_{1}=$ Barani variety, $\mathrm{V}_{2}=$ Hybrid $\mathrm{F} 1$ variety

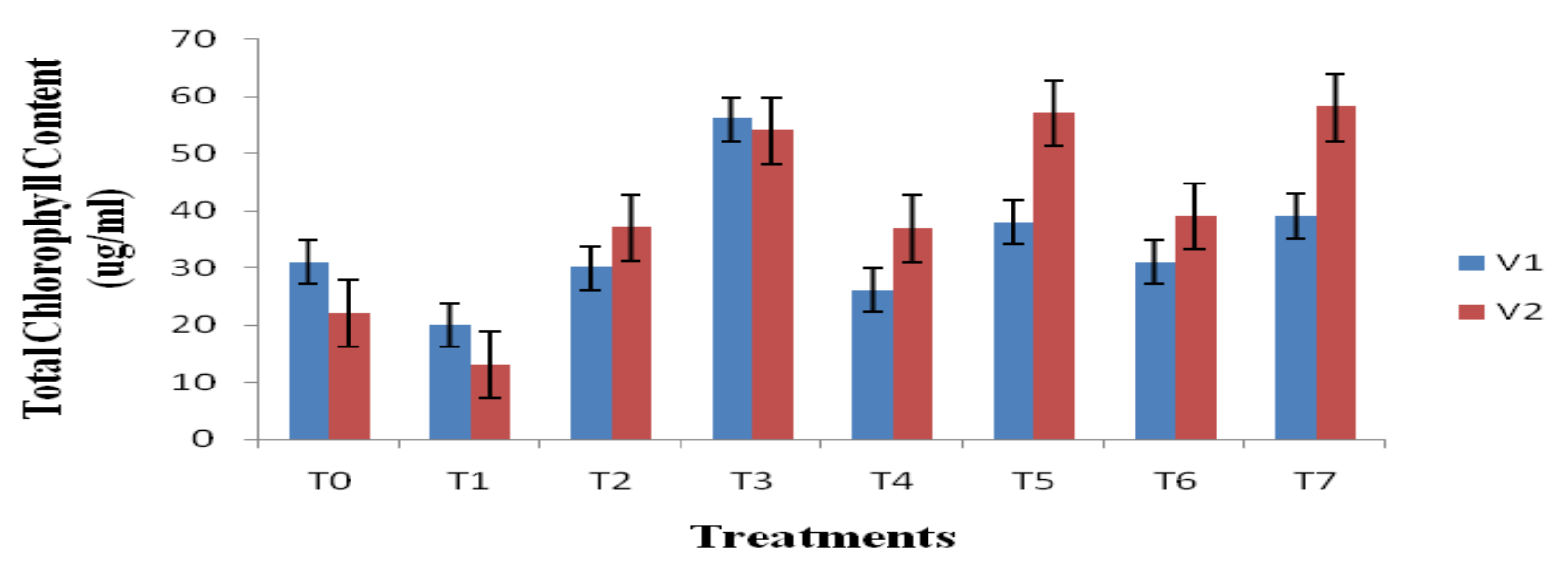

Fig.7. Effect of compost and NPK on total chlorophyll content of two pea varieties under drought stress Where $\mathrm{T}_{0}=$ Control \pm well-water condition, $\mathrm{T}_{1}=$ Control \pm drought stress, $\mathrm{T}_{2}=$ Compost \pm well-water condition, $\mathrm{T}_{3}=$ Compost \pm drought stress, $\mathrm{T}_{4}=\mathrm{NPK} \pm$ well-water condition, $\mathrm{T}_{5}=\mathrm{NPK} \pm$ drought stress, $\mathrm{T}_{6}=$ Compost and NPK \pm well-water condition, $\mathrm{T}_{7}=$ Compost and $\mathrm{NPK} \pm$ drought stress. And $\mathrm{V}_{1}=$ Barani variety, $\mathrm{V}_{2}=$ Hybrid $\mathrm{F} 1$ variety 
$33 \%$ as compared to control under drought as shown in fig.5.

Compost had increased Chlorophyll b of Barani variety about $29 \%$ and Hybrid variety about $40 \%$ as compared to drought control. NPK had increased chlorophyll b of barani variety is $46 \%$ and Hybrid variety is $19 \%$. The combined effect of compost and NPK had increased chlorophyll $b$ of Barani variety is $43 \%$ and Hybrid variety is $18 \%$ as compared to control under drought as shown in fig.6. Compost had increased total chlorophyll content of Barani variety about $35 \%$ and Hybrid variety about $24 \%$ as compared to drought control. NPK had increased total chlorophyll content of Barani variety is $52 \%$ and Hybrid variety is $22 \%$. The combined effect of compost and NPK had increased total chlorophyll content of Barani variety is $51 \%$ and Hybrid variety is $22 \%$ as compared to control under drought as shown in fig.7. These results are in agreements with previous reports [7, 9-15].

\section{References}

1.Zajac T, Klimek-Kopyra A \& Oleksy (2013). Effect of Rhizobium inoculation of seeds and foliar fertilizeration on productivity of Pisum sativum L. Acta Agrobotan. 66(2): 71-78.

2. Bozoulu H, Pekben E \& Mser AGI (2004). Sora aralouo ve potasyumkumat uygulamasonon bezelyenin verim ve bazozelliklerine etkisi. ltesi Tarom Bilimleri Dergisi. 10(1): 53-58.

3. Kaya MD, Ifti CY \& Kaya M (2002). Bakteri abolamaso ve azot dozlaronon bezelye (Pisum sativum L.) ode verim ve verim. ouelerine etkileri. ltesi Tarom Bilimleri Dergis. 8(4): 300-305.

4. Singh HB \& Joshi BS (1970). Pulse crops in India, Indian council of Agricultural Research, New Delhi.

5. Vahidim J (2009). Effect of water stress on germination indices in seven wheat cultivar. World Acad. Sci. Engin. and Techn., 49.

6. Galies J \& TDH (1983). Multiple molecular forms of the gibberellininduced 5-amaylase from the aleurone layer of barley seeds. Arch Biochem. Biophys. 224.

7. Farooq M, Wahid A, Kobayashi N, Fujita D \& Basra SMA (2009). Plant drought stress effects, mechanisms and management. Agron. Sustain. Dev. 29: 185-212.

8. Kage H, Kochler M \& Stützel H (2004). Radicle growth and dry matter partitioning of cauliflower under drought stress condi-tions: measurement and simulation. Euro. J. Agron. 20: 379-394.

9. Pessarakli M (1999) Handbook of plant and crop stress. 2nd Ed., New York: Marcel Dekker Inc 247-259.

10. Higa T (1994). The Complete Data of Em Encyclopedia. 2nd e.d. SogoUnicom in Japanese, Tokyo, pp. 385-388.

11. Mishra N (2014). Growth and yield response of pea (Pisum sativum L.) to Integrated Nutrient Management- A Review. J Plant and Pest Sci. 1(2): 87-95.

12. Hesse PR (1971). A text book of soil chemical analysis. John Murray London. 52 .

13. Bruinsma, CJ (1963). The quantitative analysis of chlorophyll a and $\mathrm{b}$ in plant extract. J phytochem. and photobiol. 2: 241-249.

14. Chuhan HS, Joshi SC, \& Rana DK (2010). Response of vermi-compost on Growth and Yield of Pea (pisum sativum L.). J Nature and Sci. 8(4): 18-21.

15. Sarwar G, Hussain N, Schmeisky H \& Muhammad S (2007). Use of compost an environment friendly technology for enhancing rice-wheat production in Pakistan. Pak. J. Bot. 39(5): 1553-1558. 